\title{
Contexto arquitectónico y desarrollo tecnológico del Cine Monumental de Teodoro Anasagasti
}

\section{Architectonic context and technological implements for Teodoro Ansagasti's Monumental Cinema}

\author{
A. Lavilla ${ }^{(*)}, \underline{\text { C. Martín Gómez }}{ }^{(*)}$, J. M. Pozo ${ }^{(*)}$
}

\section{RESUMEN}

La superación de la crisis que caracterizó la economía española en los años veinte permitió que pudiesen construirse más edificios y que fuese posible seguir los conceptos de las corrientes modernas europeas. Los cines fueron uno de los géneros más dados a ese intento de modernidad. Existen pocos ejemplos de verdadera calidad arquitectónica, y la mayoría de ellos se edificaron en las grandes ciudades, como Madrid y Barcelona. Y es en este contexto donde cobra todo sentido rescatar del pasado una de las grandes obras construidas en aquellos años: el Cine Monumental de Teodoro de Anasagasti, aportando datos arquitectónicos y tecnológicos adicionales a la historiografía existente.

Palabras clave: arquitectura; cine; instalaciones; construcción; integración.

\section{ABSTRACT}

Overcoming the economical crisis that Spain suffered in the twentieth century allowed to build more edifices and made possible to follow the concepts of modern European movement. Cinemas were one of the best examples of this attempt of modernity. There are few examples of real quality architecture, and majority of them were built in Madrid or Barcelona. In this context, one of that years' greatest works has to be put in value: Teodoro Anasagasti's Monumental Cinema, providing additional architectonic and technological data to the existing historiography.

Keywords: architecture; cinema; building services; construction; integration.

(*) Universidad de Navarra, Pamplona (España).

Persona de contacto/Corresponding author: cmargom@unav.es (C. Martín Gómez)

ORCID: http://orcid.org/oooo-0001-8871-8663 (A. Lavilla); http://orcid.org/oooo-0oo3-0150-1686 (C. Martín Gómez); http://orcid.org/oooo-0003-2444-8822 (J. M. Pozo)

\footnotetext{
Cómo citar este artículo/Citation: Lavilla, A., Martín Gómez, C., Pozo, J. M. (2017). Contexto arquitectónico y desarrollo tecnológico del Cine Monumental de Teodoro Anasagasti. Informes de la Construcción, 69(546): e197, doi: http://dx.doi.org/10.3989/ic.16.006.

Copyright: (C) 2017 CSIC. Licencia / License: Salvo indicación contraria, todos los contenidos de la edición electrónica de Informes de la Construcción se distribuyen bajo una licencia de uso y distribución Creative Commons Attribution License (CC BY) Spain 3.o.
} 
El objetivo principal de este texto es definir el contexto arquitectónico y el desarrollo tecnológico que permitieron alcanzar el grado de calidad final del Cine Monumental. No obstante, se considera conveniente aportar unas breves líneas sobre la figura del arquitecto Teodoro Anasagasti para comprender mejor el entorno histórico y cultural de la época.

Nacido en Bermeo (Vizcaya), procedente de una familia humilde, llegó a Madrid en 1896 a la edad de 16 años para realizar sus estudios de arquitectura. Obtuvo la titulación de arquitecto por la Escuela de Arquitectura de Madrid en el año 1906, para volver poco después a su pueblo natal, en donde fue nombrado Arquitecto Municipal en $1907^{1}$ (1) (2) (3) (4) (5) (6).

Uno de los más importantes legados de la obra de Anasagasti (desaparecida en buena parte) fue el de las obras relacionadas con el mundo del espectáculo: cines, teatros y salas de baile. Desarrolló con los cines una tipología propia, haciendo que su sencillez y orden los acercase al Movimiento Moderno. Así, cines madrileños como el Real Cinema, el Monumental Cinema, El Cisne o Chueca, El Pavón, junto a las reformas acometidas en el Príncipe Alonso, Fuencarral o Gong, formaron parte de la interesante labor que desarrolló Anasagasti con esta nueva tipología. Con ellos definió la fisonomía del nuevo cine y buscó los tipos de materiales de construcción idóneos, asociando a su construcción la explotación del potencial técnico y expresivo del hormigón ${ }^{2}$.

\section{LOS CINES DE ANASAGASTI: EL PROTOTIPO DE UNA ÉPOCA}

Como se ha señalado, Anasagasti era un hombre con muchas inquietudes intelectuales y sociales, siempre en estrecho contacto con lo que ocurría a su alrededor. Hacia 1918, tras la primera gran guerra europea, comenzaron tiempos más prósperos para todo occidente. Sin embargo, en España el desarrollo económico empezó a decaer a partir de esta fecha, dando lugar a retrasos y desigualdades respecto al resto de Europa.

A pesar de que la penuria económica y la situación social sufrida por nuestro país apenas permitieron construir edificios, y menos aún conforme a las reglas estéticas de la modernidad hasta finales de los años cuarenta, sí se construyeron gran cantidad de cines. La misma naturaleza del cine y su rápida difusión y aceptación social introduce dos notas importantes en la cuestión que afectan radicalmente a su diseño. La primera que las salas debían mostrar con evidencia la modernidad que ofrecían en su interior: tenían que reflejar inmediatamente la moda estética imperante. Pero sobre todo el cine fue una actividad muy lucrativa y por eso mismo los promotores podían permitir a los arquitectos audacias y gastos inimaginables en la construcción de otro tipo de edificios.
A excepción de algunas tendencias historicistas, la mayoría de arquitectos se decantó por estilos más renovadores a la hora de edificar sus cinematógrafos. El cine, como espectáculo reformador del nuevo siglo, representaba una gran oportunidad para los arquitectos innovadores, que no entendían el cine como otro tipo de "teatro», de ejemplificar la idea de «lo moderno». Sin un estilo decimonónico que lo precediese, entre el cine y la edificación que lo alojaba se producirá una relación muy sugestiva.

Los ecos de la arquitectura alemana y de otras corrientes vanguardistas europeas se dejaron sentir a través de la amplia acogida que recibieron en las revistas de arquitectura españolas, en especial en Arquitectura. La publicación de Zucker sobre teatros y cines en 1926 dio a conocer un amplio repertorio de obras interesantes y nuevas construcciones, como el cine Capitol de Poelzig en Berlín (1925) o el Universum de Mendelsohn (1928), que tuvieron rápidas repercusiones (8) (9) (10) (11) (12) (13) (14) (15) (16) (17) (18).

Aunque los cines fueron uno de los géneros más dados a ese intento de modernidad, existen pocos ejemplos de verdadera calidad arquitectónica en España, y la mayoría de ellos se edificaron en las grandes ciudades, como Madrid y Barcelona. Por ello los cines madrileños de Anasagasti permiten hacer un recorrido por los cambios fundamentales que experimentaron los cinematógrafos durante esta época y a la vez constatan los avances tecnológicos y estéticos que se iban observando. Además, estos cambios apreciados en la arquitectura cinematográfica madrileña se imitaron en el resto de España (19) (20) (21).

El estudio de Anasagasti se sirvió de esta coyuntura, situándose como pionero de este tipo de locales. Aprovechando su relación con Carlos Viñas Sagarra, dueño de la empresa Sagarra que gestionaba estas salas en Madrid, recibió su primer gran encargo, el Real Cinema, inaugurado en 1920. Mientras tanto elaboró el proyecto de reforma del Teatro Príncipe Alfonso y el proyecto del Monumental Cinema. Como se ha señalado anteriormente, las salas de proyección tenían las características tipológicas y espaciales propias de los teatros, adaptándose mal a su nuevo uso, o eran construcciones provisionales realizadas con materiales pobres y que creaban verdaderas situaciones de peligro para el público. Por ello, Anasagasti decidió establecer una serie de reglas para resolver las salas dando una respuesta óptima a los requisitos del cine moderno, y dotándolas de la dignidad acorde a la importancia adquirida por el fenómeno cinematográfico en las ciudades. Así, en 1919 publicó un artículo en la revista $L a$ Construcción Moderna (22) como una respuesta técnica a los problemas que planteaba la edificación de cines modernos y estableciendo por primera vez un programa singular que precisaba de una nueva forma, claramente diferenciada del tipo decimonónico adecuado para los teatros.

\footnotetext{
${ }^{1}$ Durante su viaje Anasagasti se interesó por conocer las obras más destacadas de las vanguardias arquitectónicas, pero también por bucear en los planes de estudios de unos centros de enseñanza que, en su opinión, eran capaces de proporcionar al alumnado una formación acorde con los nuevos tiempos. Regresó a Madrid en 1915 y fue contratado como profesor auxiliar en la Escuela de Arquitectura, llegando a ser nombrado Catedrático de Proyectos y de Historia de la Arquitectura (7).

2 En sus primeros años podemos apreciar una creciente influencia de las corrientes Art Nouveau y sobre todo de la Secesión Vienesa. Más tarde siguió modelos internacionales y eclécticos (en colaboración con su suegro López Salaberry) para algunos edificios madrileños, y fue regionalista cuando intervino en pequeñas ciudades de provincia. Encontraba evidentes virtudes en la arquitectura popular, pues pretendía emplear el hormigón armado con la sabiduría del constructor tradicional. Por tanto, para Anasagasti ser regionalista consistía en prestar atención al lugar y a las tradiciones, materiales y técnicas locales que aceptaban la vigencia de los siglos, pero sin caer en tipismos ni rasgos folklóricos.
} 
«El teatro, con una tradición antiquísima y gloriosa, definió su fisionomía y disposición propias. El cinematógrafo, aún en mantillas, carece de carácter. Los salones donde se alberga son teatros, o, a lo más, construcciones híbridas, como los primeros automóviles, remedo de los carruajes» (22).

Su primera aportación surgió del hecho de considerar la sala de proyección como la parte fundamental del edificio, a diferencia de los teatros, donde ésta apenas conquistaba una décima parte de la superficie. En el cinematógrafo la sala abarcaría al menos dos tercios de la planta y los espacios de relación (vestíbulos, salones, escaleras), aunque holgados y cómodos, deberían relegarse a los espacios residuales, ya que los entreactos eran más cortos que en las obras de teatro y, por tanto, los salones de representación social eran menos importantes. Anasagasti percibió la necesidad de tener en cuenta el cambio en el reparto de las localidades: el público popular era el que ocupaba las primeras filas, mientras que las más ansiadas de los teatros retrocedían hasta las últimas o, incluso, subían al anfiteatro.

Efectivamente, debía investigarse en nuevas estructuras que creasen grandes voladizos para este anfiteatro, sacrificando los peores asientos de la planta baja. La planta en herradura o semicircular que potenciaba la acústica carecía ahora de sentido y tenía que cambiarse por una forma trapezoidal, con las paredes convergentes hacia la pantalla y los asientos dispuestos en arcos de círculos concéntricos. Un elemento propio de la nueva tipología como era la cabina de proyección debía manifestarse en la sala, prestando especial atención a la protección contra incendios, ya que las películas eran inflamables, por lo que era necesario construirla con materiales refractarios y cierres automáticos para ahogar un posible fuego.

«Un elemento nuevo, la cabina, se manifiesta en la sala. Tal como hoy se proyecta ha de situarse en el fondo, bajo el anfiteatro, o encima, cerca del techo; mejor, debajo, por ser más normal la proyección. Se indica también como lugar de emplazamiento de la cabina las primeras filas del anfiteatro, por la claridad y economía del fluido eléctrico; solución que tiene graves inconvenientes: pérdida de las mejores localidades, difícil acceso del operador, poca independencia del público y limitación del espacio disponible» (22).

Asumiendo que el cinematógrafo era una cámara oscura donde los colores claros y las armonías brillantes debían de quedar proscritos para lograr una proyección precisa de la imagen en la pantalla, esta condición tenía necesariamente que manifestarse en la fachada para que desde el exterior se intuyese el uso del inmueble. Por tanto, el edificio precisaba sólo los huecos indispensables para poder iluminar los vestíbulos u otras salas comunes, lo que permitía cegar las fachadas convirtiéndolas en soportes publicitarios para los carteles.

«Se nos olvidaba, al hablar de las fachadas, mentar las grandes carteleras para los afiches; nuevo auxiliar de la propaganda, que el arquitecto como tantas otras circunstancias, debe traducir en la disposición si se preocupa del carácter» (22).

Además, desde el IX Congreso Internacional de Arquitectos celebrado en Roma en 1911 (23), Anasagasti se había conver- tido en el abanderado de la defensa del hormigón armado como material de gran potencial tanto técnico como expresivo, frente a los que sólo lo encontraban adecuado para realizar obras de carácter industrial.

Tras sentar las bases de la nueva tipología, Anasagasti redactó un proyecto de cine para la villa de Sestao (que no llegó a construirse) y otro para la madrileña plaza de Chamberí (desaparecido). Al año siguiente llevó a cabo el proyecto de reforma del teatro Novedades (que fue pasto de las llamas) y ya en el año 1924 una ambiciosa reforma del teatro Fuencarral, que quedó finamente reducida a una mínima intervención. Un año más tarde inauguró el Teatro Pavón, recientemente recuperado. Mientras trabajó en el Teatro Villamarta en Jerez de la Frontera, último proyecto de esta tipología donde consiguió aunar su mundo intelectual y utópico con su faceta de técnico experimentado (24).

\section{CONTEXTO TECNOLÓGICO}

Las técnicas de ventilación y acondicionamiento de aire experimentan un gran progreso a partir de 1920, usándose instalaciones de climatización centralizadas en teatros, cines, oficinas, salas de conferencias y en la industria, especialmente la dedicada a la elaboración de materias como el tabaco o el papel, usándose por primera vez, las máquinas frigoríficas de amoniaco o ácido carbónico como medios refrigerantes para el enfriamiento y la deshumidificación del aire (25).

El premeditado aire acondicionado de los cines de los Estados Unidos llegó sólo en 1922, lo que parece ser definitivamente posterior al comienzo del control continuo de la humedad en el Royal Victoria Hospital (26).

En este panorama destaca la publicación, en 1929, de la revista titulada Heating, Piping and Air Conditioning; el título, con el uso de la palabra 'aire acondicionado' es una señal de que el término es de uso común. El artículo principal del número de julio proclama que el Milam Building en San Antonio, Texas, es el primer edificio en el país en estar completamente equipado con aire acondicionado. El sistema instalado presenta varias interesantes particularidades: el condensador de agua enfriada utiliza el río cercano; un depósito de agua enfriada que «se carga» durante la noche, se emplea para enfriar y deshumidificar durante la siguiente jornada; además, los ocupantes de las oficinas pueden elegir entre abrir las ventanas o utilizar el aire acondicionado (26).

En 1929, también en la revista Heating, Piping and Air Conditioning, se afirma que los edificios sin ventanas «ya imaginados por algunos y posibilitados por el aire acondicionado y la iluminación artificial, se harán realidad con toda seguridad... Se les debería recordar a los que reivindican el aire «fresco» de las ventanas abiertas que eso no existe en la ciudad congestionada... Así que el aire acondicionado ha llegado para garantizar cada día lo mejor en confort atmosférico, cosa que la naturaleza ofrece muy de vez en cuando» (27).

En España, los antecedentes del acondicionamiento ligados a la arquitectura quedan mayoritariamente dentro del ámbito de la arquitectura industrial y hospitalaria durante mucho tiempo. Las técnicas de ventilación y acondicionamiento de aire experimentan un gran progreso a partir de 1920, usándose instalaciones de climatización centralizadas en teatros, cines, oficinas, salas de conferencias y en la industria, especialmente 
la dedicada a la elaboración de materias como el tabaco o el papel $^{3}$. Los nuevos métodos de la ingeniería reducen los costes de la operación, haciendo que el aire acondicionado sea más atractivo para los responsables de los teatros, los cuales empiezan a renovarse en la década de los veinte. Así, de los cuatro teatros refrigerados en Chicago en 1922, se pasa a 14 tres años más tarde, y en 1927 se han proyectado 50 teatros refrigerados; un crecimiento que propicia la reducción de los costes de instalación y mantenimiento (28). Un artículo publicado por Fred Wittenmeier, en julio de 1922, titulado «Ice and Refrigeration», se refiere al enfriamiento de teatros y edificios públicos, proporcionando algunas reglas generales para la refrigeración de teatros, tales como que en los estados del norte son necesarios $9 \mathrm{~kW}$ para un caudal de aire de $472 \mathrm{l} / \mathrm{s}$, potencia a la que hay que añadir un $25 \%$ en las áreas del sur ${ }^{4}$.

A partir de los años veinte la implantación de las tecnologías disponibles en el extranjero se trasplanta con cierta celeridad en España (Figura 1), y de hecho los sistemas de aire acondicionado se comienzan a implantar masivamente en espacios públicos, gracias al crecimiento del número de cines y teatros en Madrid en las décadas de los veinte y treinta, generando interesantes ejemplos, como el Teatro-Cinema Monumental del arquitecto T. de Anasagasti (1923) el cual «se dota de un ineludible sistema de calefacción/ventilación a cargo del ingeniero Jacobo Schneider» (30).

\section{EL CINE MONUMENTAL}

El Monumental Cinema es una de las obras más importantes de Anasagasti dentro de esta tipología. Fue realizado en 1922
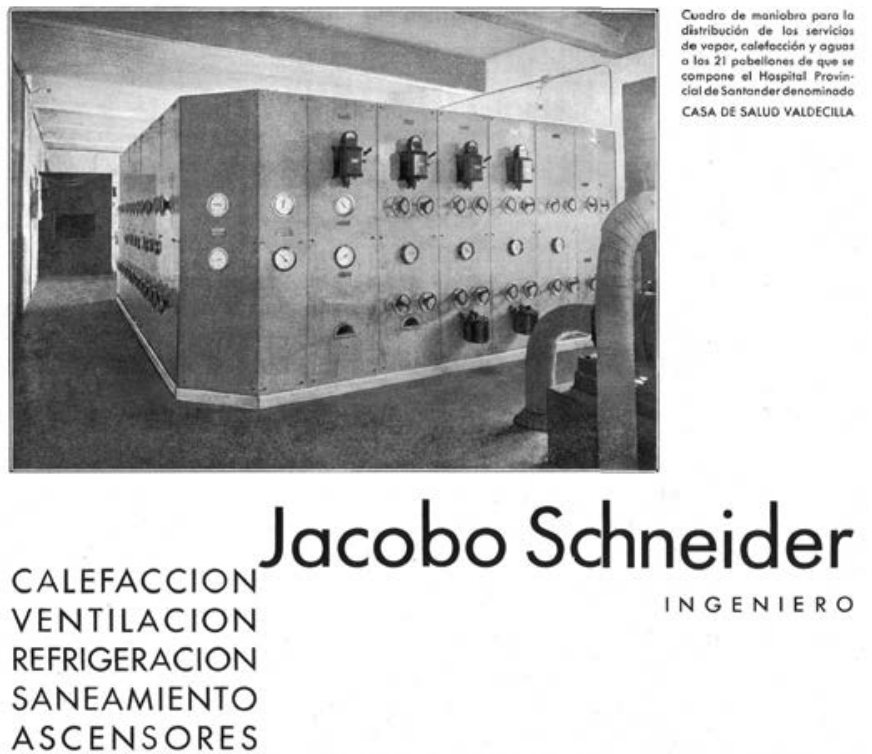

\begin{tabular}{l} 
N. AlCALÁ ZAMORA, 32 - MADRID \\
DELEGACIONES: \\
BARCELONA: CORTES, 617 - BILBAO: M. DEL PUERTO, 7 \\
\hline
\end{tabular}

Figura 1. Publicidad sobre instalaciones de climatización aparecida en España a principios de la década de los años treinta. por encargo de la empresa Sagarra, sobre un irregular solar que había acogido el Real Hospital de Aragoneses, Catalanes y Valencianos, demolido en el siglo XIX. Como en el Real Cinema, el edificio se levantaba en un espacio abierto, con la entrada principal situada en la madrileña plaza de Antón Martín y un estrecho frente que aparecía en la calle del León (Figura 2). El cine duplicaba los aforos normales de la época, con 4.00o localidades sobre una superficie de $1.407 \mathrm{~m}^{2}$, lo que permitía una superficie por espectador de $0,35 \mathrm{~m}^{2}$. El proyecto preveía la comunicación directa con una estación de metro próxima, que se estableció en 1923.

El tortuoso emplazamiento del Cinema Monumental no permitía el desarrollo de un local con las condiciones de rotundidad espacial que solía requerir la arquitectura cinematográfica. Sin embargo, Anasagasti logró insertar un edificio de apariencia simétrica aprovechando los recovecos y salientes del solar para emplazar en ellos los espacios accesorios (como aseos y almacenes) y los elementos de comunicación vertical.

«El Monumental está en solar irregular, de veintidós lados, nada menos, y hasta donde es posible dentro de ese dédalo, se ha levantado el edificio armónico. [...] En los rincones se dispusieron los patios, escaleras y cabina.

Podría haber sido la sala completamente simétrica y regular, desperdiciando mucho terreno; mas, siendo tan grande el solar, no era preciso llegar a tales derroches y mantener con exageración la simetría, por no apreciarse bien de cada extremo las irregularidades de los otros.

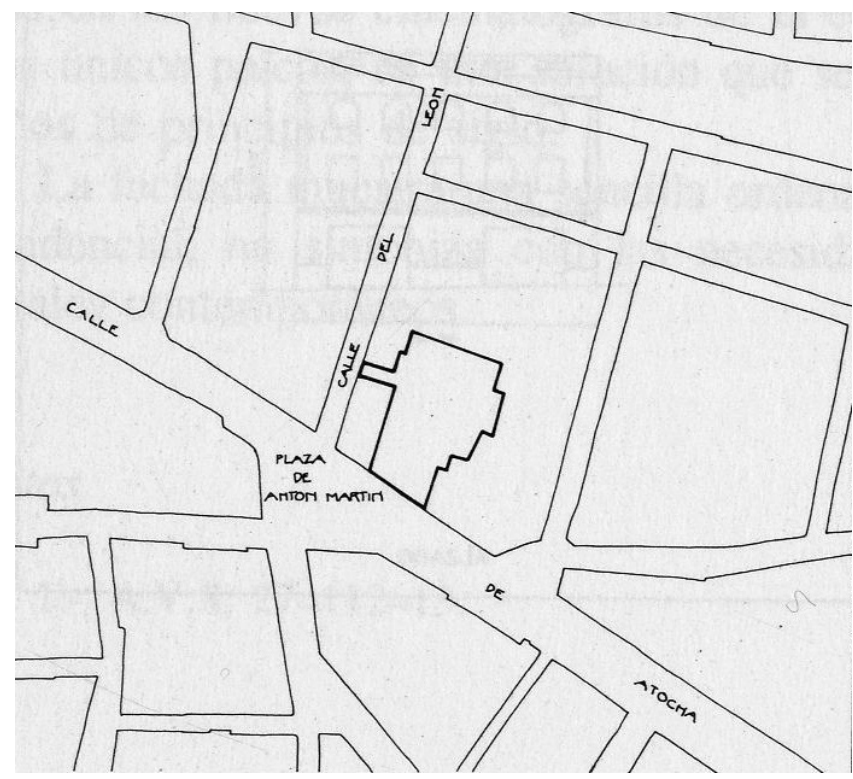

Figura 2. Monumental Cinema, planta situación en

Fernández Muñoz, Á. L. Arquitectura teatral en Madrid, del corral de comedias al cinematógrafo, Editorial El Avapiés, Madrid, 1988.

\footnotetext{
3 «Se usaron, por primera vez, las máquinas frigoríficas de amoniaco o ácido carbónico como medios refrigerantes para el enfriamiento y la deshumidificación del aire» (25).

4 Los primeros sistemas de refrigeración en teatros utilizan sistemas de expansión directa con dióxido de carbono, del mismo tipo que el instalado en 1911 en el teatro Orpheum de Los Ángeles, cuyo equipamiento es de la «Kroeschell Brothers Ice Machine Company» (29). Esta instalación probablemente es diseñada por Frederick Wittenmeier, quien más tarde realizaría numerosos sistemas de enfriamiento por aire para teatros (28).
} 


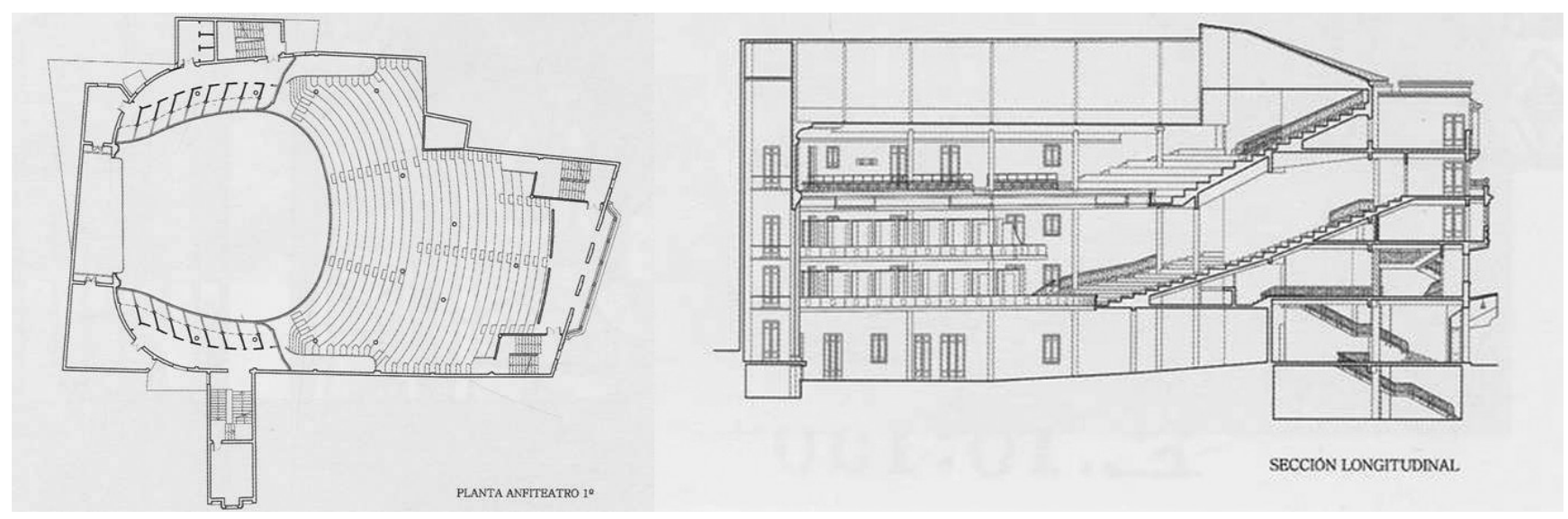

Figura 3. Monumental Cinema, planta y sección longitudinal en (24).

En el papel no es fácil -por esa razón- la forma de la sala. Mas, dentro de ella, es otra cosa»5.

Siguiendo los cánones que el propio arquitecto había puesto en marcha en el Real Cinema, la sala ocupaba casi la totalidad de la planta y contaba con anfiteatros que volaban ampliamente sobre el patio de butacas, sacando el máximo aprovechamiento del espacio disponible y reforzando la unidad del conjunto (Figura 3). La sala se separaba de la fachada por un vestíbulo de notables dimensiones, flanqueado por las dos escaleras principales.

A pesar de no contar con la posición en esquina en la que desarrollar el clásico torreón de sus principales cines, Anasagasti conservó en lo demás su modo habitual de resolver los exteriores: la proyección en cuerpos diferenciados del espacio interior sobre la imagen del alzado. Así pues, la disposición anterior del vestíbulo situado entre dos escaleras se traducía en una organización tripartita de la fachada principal con un cuerpo central, que tenía una galería abierta en la primera planta y otra cerrada en la segunda, rodeado por dos volúmenes laterales más altos (Figura 4).

La entrada se producía a través de tres arcos de medio punto cubiertos por una marquesina de losas de hormigón, con una imagen muy diferente a la que ofrecían los voladizos de hierro habituales en el Modernismo. El resto de huecos de la fachada eran adintelados, contrastando con estos tres elementos semicirculares. Los paños lisos que enmarcaban el acceso permitían la colocación de carteles publicitarios.

La estrecha fachada a la calle del León, que en planta baja albergaba la salida de emergencia, es el único vestigio que permite recordar el alzado principal (Figuras 4 y 5), ya que, al contrario que éste, se conserva tal y como fue construida.

La diferenciación con los edificios colindantes se consigue a través de dos machones de ladrillo que contrastan vivamente con la horizontalidad del cuerpo de ventanas corridas. La composición de las fachadas se basaba en la claridad de diseño y el equilibrio logrado entre las líneas verticales y horizontales, sin necesidad de recurrir a los ornamentos que revestían los edificios contemporáneos.
En el interior, Anasagasti también utilizó un sistema decorativo elemental para exprimir al máximo las posibilidades estéticas del hormigón armado. Los elementos estructurales eran los auténticos protagonistas del espacio, dejándolos vistos y sin más decoración que unos leves ornamentos pictóricos. Los nudos de los diferentes órdenes estructurales, como los apoyos en ménsula de las vigas sobre los pilares o la sucesión de los cantos de las viguetas creando falsos techos, constituyen el sistema decorativo. Esto quedaba patente en la sala, pero aún más en el diseño de las partes auxiliares del edificio, como el bar ubicado bajo el segundo anfiteatro, donde Anasagasti desplegó su concepción más radical de una nueva expresión ornamental del hormigón.

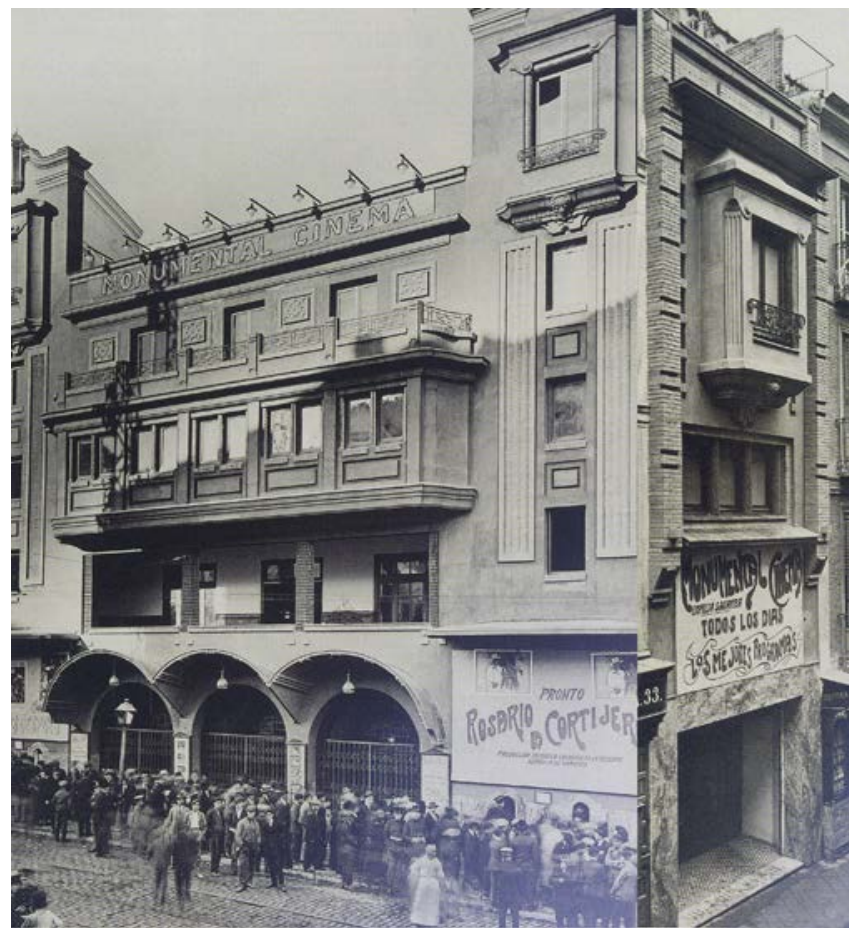

Figura 4. Monumental Cinema, fotografías de época del alzado principal (izquierda) y fachada de la calle del León (derecha), en «La película del cine» en La Construcción Moderna, n. ${ }^{\circ} 21$, noviembre 1923, pp. 325 y 328 , respectivamente.

\footnotetext{
5 La revista La Construcción Moderna dedicó al Cine Monumental una serie de artículos recogidos en un número monográfico (n. 21 noviembre 1923) donde se explicaban las características del edificio, desde su proceso de construcción hasta las reacciones que suscitó en el público y la crítica (31).
} 

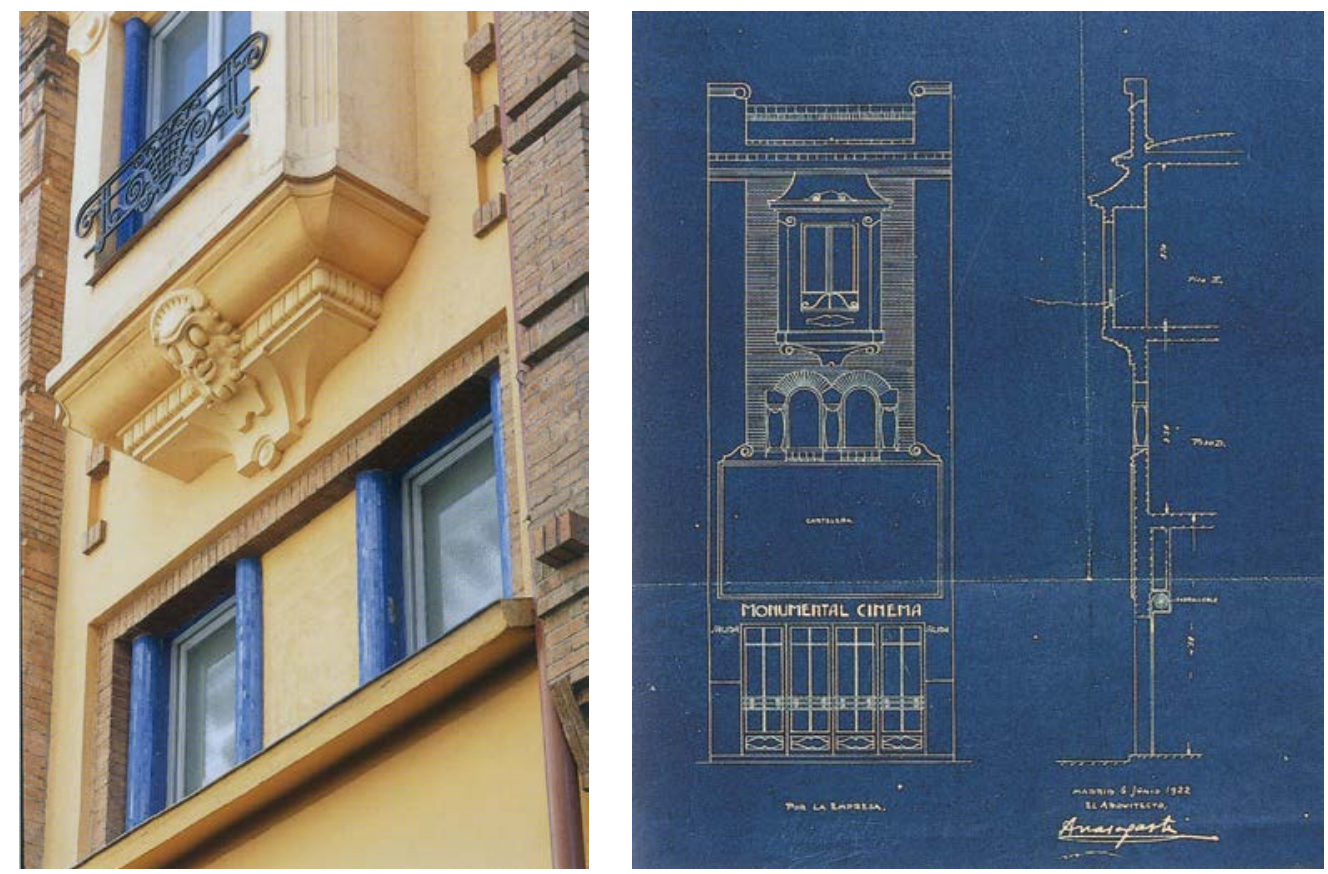

Figura 5. Monumental Cinema, fachada a la calle del León en su estado actual (izquierda) y en un plano de Teodoro Anasagasti (derecha) en (24).

Las luces y dimensiones del Monumental Cinema excedían de lo normal en este tipo de locales. Toda la estructura del edificio fue construida en hormigón armado, ejecutado por la Sociedad de Cementos Portland de Sestao y revisada mediante pruebas de resistencia con sobrecargas de 400 y 500 $\mathrm{kg} / \mathrm{m}^{2}$ durante 25 días, a excepción de la cubierta formada por grandes cuchillos metálicos calculados por el ingeniero Celso Máximo, especializado en este tipo de obras, que descansaban sobre cuatro apoyos, dos a cada lado de la sala (32) (Figura 6).

Los vuelos, incluso mayores que en el Real Cinema, eran sostenidos por esbeltos soportes que provocaron el temor del público y de las autoridades. De hecho, la Junta de Espectáculos obligó a comenzar las proyecciones con un anuncio en la pantalla que indicase que el abandono del local, en caso de alarma, se hiciese con calma; además, la empresa debía colocar indicadores y dependientes en cada una de las salidas y reducir el número de espectadores en los anfiteatros. Anasagasti, resentido ante el miedo irracional que las autoridades mostraban frente al nuevo material, pensó incluso en seguir el ejemplo de un empresario barcelonés que había engrosado las columnas metálicas que sujetaban su anfiteatro con gruesos fustes de escayola (32). En todo caso decidió proyectar durante varios días fotografías de las pruebas de carga de los diferentes elementos para garantizar al público que se encontraban en un local seguro (Figura 6).

Por tanto, el interés de Anasagasti por el hormigón armado excedía el simple uso técnico para resolver grandes luces. A través de su reflexión «La belleza del cemento armado» defendía el respeto por las formas sencillas, sin ningún tipo de enmascaramiento, que el hormigón debía adquirir en base a la resolución de las tensiones estructurales y de los principios de su comportamiento mecánico:

«Si buscamos el aplauso de cierto público, y no el racionalismo estético y la propia rigurosa satisfacción, ¿nos hubiésemos aventurado a exentar aquellas grandes superficies de aditamentos?

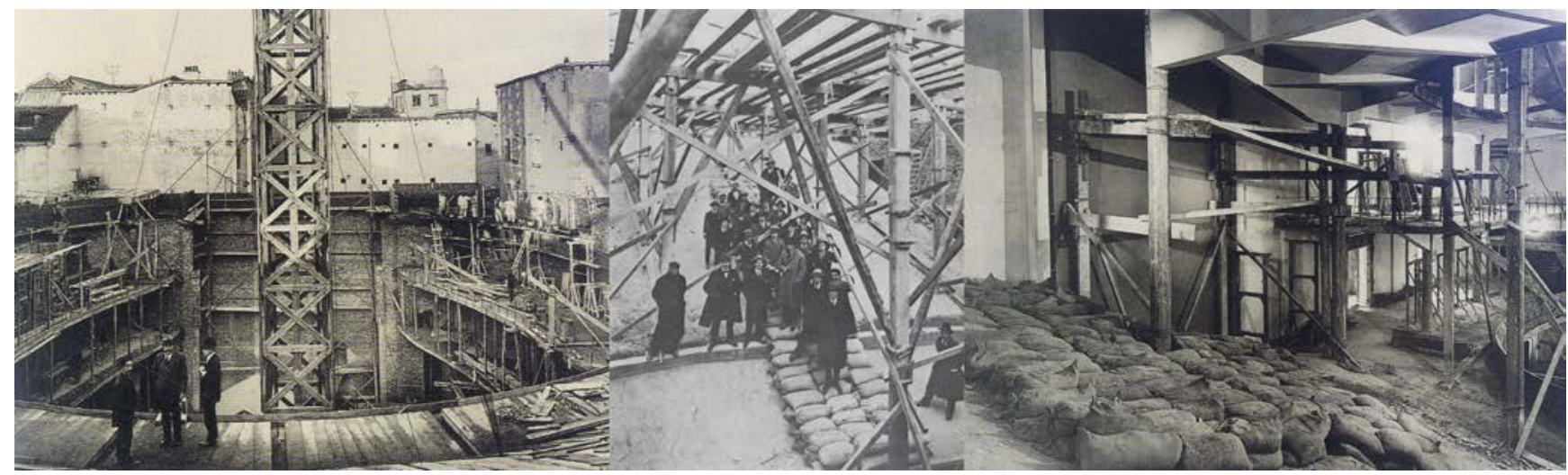

Figura 6. Izquierda: construcción de la armadura de cemento armado por la Casa Sestao. Derecha: Anasagasti junto a sus alumnos visitando las obras del Monumental Cinema. Centro inferior: pruebas de carga de la estructura. En «Homenaje Anasagasti», Revista Nacional de Arquitectura, n. ${ }^{\circ}$ 240, enero-febrero, 1983. 
¿Es lógico que las viguerías de hierro y cemento armado se escondan detrás de techos planos, y que de éstos se cuelguen magníficas vigas y artesonados de yeso? Si la misma estructura nos trae vigas, justo es que la respetemos. La viguería de cemento tiene una fisonomía propia, muy moderna, que, por su separación y gran altura, no se parece a los entramados horizontales de madera ni hierro. [...] ¿Qué son irregulares y, al parecer, extrañas algunas soluciones? Mejor que mejor. Ellas serán la gracia, lo insospechado, lo picante de la estructura. El cemento armado tiene una belleza suya, belleza científica que hay que respetar, y no negarla, aunque a muchos les parezca horripilante. [...] El cemento armado se compondrá de hierro y conglomerado de cemento; pero adheridos tan reciamente, con tan penetrante introducción, que el cuerpo inerte de hormigón, animado por el alma metálica, se convierte en un ser vivo, animoso y firme» (32).

Habiendo proscrito la decoración con molduras y yesos, Anasagasti recurrió al adorno mediante la policromía, rememorando así su época como pintor y logrando efectos escenográficos propios de un cine moderno. Así, el bermeano rechazó los grises y con ayuda de los maestros pintores Amador Serrano, padre e hijo, eligió para el interior y las fachadas del Monumental una gama cromática que ya había ensayado tímidamente en el Real Cinema. Dentro de cada dependencia el color era distinto: azules y violetas el vestíbulo principal y el bar, verdes y amarillas las cajas de escaleras, dorado el techo de la sala aumentando de intensidad hasta el rojo veneciano del piso de butacas (Figura 7). Estas tonalidades, así como el lucernario central pendiente del techo, dotaban a la sala del Monumental de un toque oriental que la pone en relación con las fantasías japonesas tan en boga en los cinematógrafos estadounidenses y franceses de estilo Art Decó de la época (33).

La pintura aplicada en los diferentes ámbitos, de tendencias modernas, le aproximó a la campaña iniciada poco antes por Bruno Taut, a la cabeza de un grupo de jóvenes arquitectos y pintores alemanes que preconizaban las ciudades coloreadas como forma de llevar el arte a las calles (24). Pero también le permitió acercarse a las raíces profundas del arte popular y nacional, mediante la «coloración racial» con estridencias cromáticas que golpeaban la vista del espectador al provenir del arte del vulgo.

«El espectador, pasando de una sala a otra, al cambiar de ambiente lumínico y temperatura escenográfica, va recibiendo en la retina una serie de percusiones ópticas que lesionan su sensibilidad. [...] Por tener cada dependencia un color distinto, los efectos escenográficos y contrastes son grandes al mirar en el fondo de un salón coloraciones contrapuestas de las dependencias contiguas» (32).

El análisis del Monumental Cinema apunta al inmenso respeto que Anasagasti sentía por los oficios ${ }^{6}$ y la necesidad de contar con la colaboración artística de todos para conseguir la obra de arte total, que representaba su máxima aspiración (Figura 7). Por ello no dudó en buscar a las mejores marcas para que participasen en este proyecto ${ }^{7}$.

Pero al mismo tiempo Anasagasti se preocupó por los aspectos técnicos del proyecto como la protección contra incendios $^{8}$, las condiciones acústicas ${ }^{9}$ o las instalaciones de calefacción y ventilación diseñadas por el ingeniero Jacobo Schneider ${ }^{10}$. Incluso fue el primer local de Madrid en contar con un acceso directo desde el metro de la capital ${ }^{11}$.

La fisonomía de cine moderno, la sencillez en el tratamiento de los motivos ornamentales que presentaba el Monumental Cinema suscitó intensas reseñas en la prensa contemporánea $^{12}$, como la profunda sorpresa y admiración mostradas por Ramón Gómez de la Serna (35), Francisco Alcántara (36), José Francés ${ }^{13}$ o José María Donosty:

«Una gran sinceridad arquitectónica, una extrema sencillez, una absoluta ausencia de superfetación decorati-

\footnotetext{
${ }^{6}$ En el reportaje «El Edificio», dentro de «Cómo se acaban las obras: la película del cine», Anasagasti no dudó en citar y agradecer el trabajo de los diferentes maestros artesanos que participaron en la ejecución del Monumental Cinema.

7 Precisamente las lámparas (de la firma Titán realizadas con el tubo Bergman) fueron fabricadas por la renombrada casa R. Eguren de Bilbao; la casa Maumejean elaboró las vidrieras de la fachada y las lámparas y apliques de la sala y espacios secundarios; los damascos, tisús y cretonas de los palcos y puertas fueron suministrados por la casa Rodríguez Hermanos y confeccionados por el tapicero Eduardo Ruiz; el taller Garriga intervino en la carpintería; el taller de Gabriel Asins en los trabajos de hierro.

${ }^{8}$ La primera medida fue la de haber dotado al edificio con una estructura de cemento armado. El techo de la sala era de ladrillo hueco. La cabina, de cemento armado, con puerta de hierro y los aparatos Power de proyección, dispuestos de modo que sofocasen instantáneamente la inflamación de las películas. Por el edificio se distribuyó una red general de agua que contaba con 14 bocas de incendio alimentadas con tres tomas de $40 \times 6 \mathrm{~mm}$, el mismo paso de rosca que el mangaje del cuerpo de bomberos municipal. Además, en las terrazas se dispusieron otras seis bocas de incendios, a través de las cuales los bomberos podrían sofocar el posible fuego del edificio e incluso el de las casas colindantes (32).

9 Comprobadas in situ por el maestro Enrique Fernández Arbós (Director de la Orquesta Sinfónica de Madrid) y otros músicos, para su consecución se tuvieron en cuenta las leyes fundamentales de la acústica: los materiales empleados y el diseño espacial (32).

10 Para no disturbar el interior de la sala con grandes conductos, se dispusieron las instalaciones sobre su falso techo. Desde allí los aspiradores acoplados a unos motores extraían el aire viciado y, cambiando la dirección del movimiento, los mismos inyectaban aire puro (32).

${ }^{11}$ «Una de las cosas que más llamarán la atención en Monumental Cinema es el paso subterráneo que pone en comunicación el teatro con la estación del Metropolitano enclavada en la plaza Antón Martín. Mediante esta instalación, nunca vista en ningún teatro, el público puede trasladarse al Monumental Cinema sin temor al frío ni a la lluvia» (33).

${ }^{12}$ Además de servir como modelo para cines edificados en otras provincias como los llevados a cabo por el arquitecto Miguel Martín Fernández de la Torre en Canarias (34).

${ }_{13}$ «Anasagasti (...) construye en el siglo XX sin culteranismo enfadoso ni involucraciones pedantes. Si el día de mañana construye un banco (...) seguramente no empleará este simplicismo, este mastodóntico futurismo, abigarrado y sereno a la vez de sus cinematógrafos. Ni los mismos materiales. El cemento es el símbolo del siglo gris, donde fatalmente habrán de fundirse todos los colores y las cosas emblematizadas con ellos. Pero ese respeto a la estructura eminentemente estática del cemento no le hará falta tenerlo a los mármoles y los bronces de las plutocracias improvisadas, ni a las escayolas y las calaminas de las aristocracias en decadencia» (37).
} 

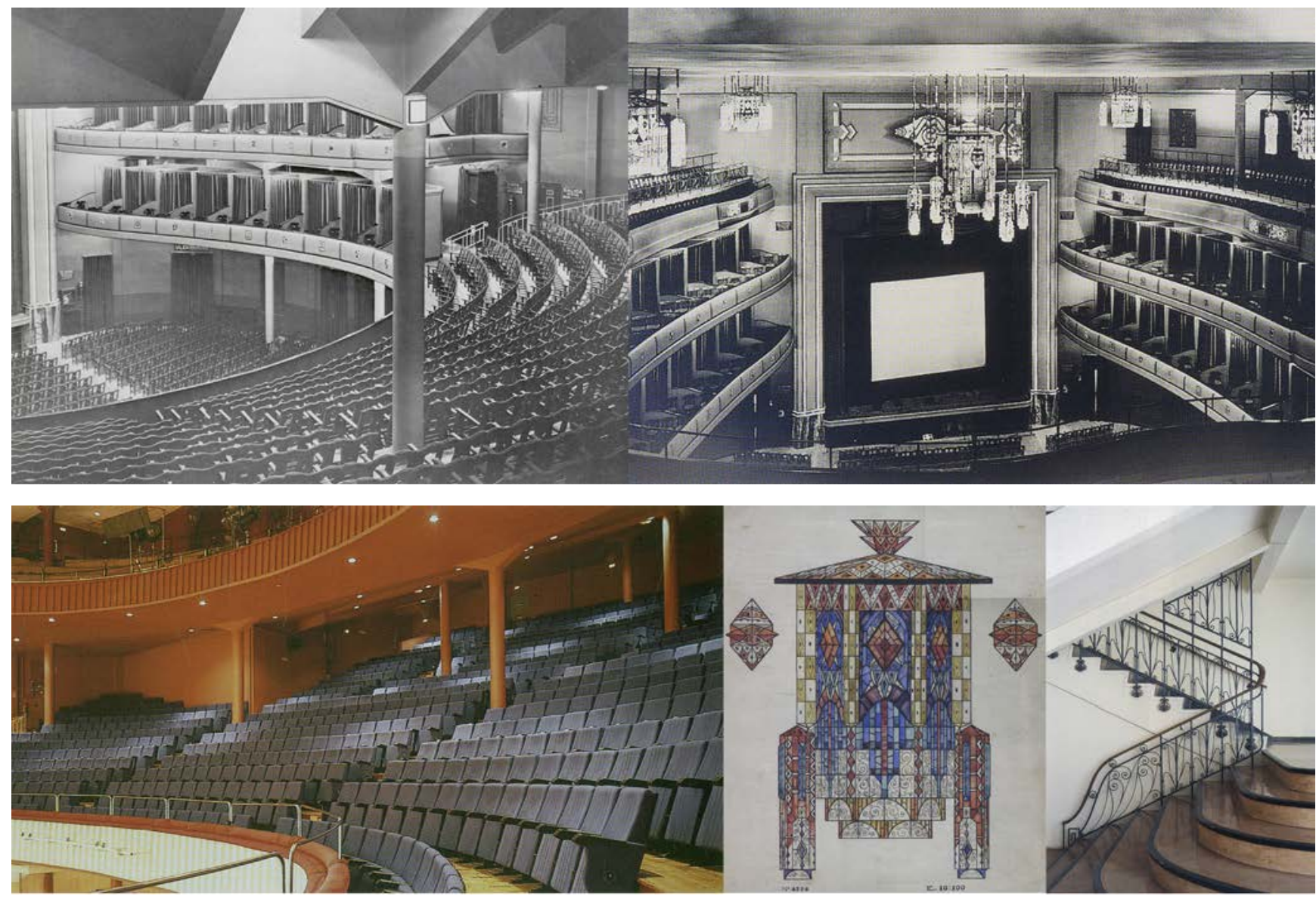

Figura 7. Arriba: Monumental Cinema, vistas de la sala principal. Izquierda, abajo: bar del piso principal, a cargo de los Sres. Echezortu y Auguiano. Las tres en «Homenaje Anasagasti» en Revista Nacional de Arquitectura, n. ${ }^{0}$ 240, enero-febrero, 1983. Centro, abajo: farolas construidas por Maumejeán Hermanos. Derecha, abajo: barandilla de la escalera del vestíbulo (maestro cerrajero Santiago López) con pasamanos y guardavivos de Jaime Ruiz. Ambas en en (24).

va, el empleo de colores sin mezcla, un techo plano, un alumbrado opaco, y los espectadores alejados por grandes masas; he ahí algunos de los rasgos principales de esta obra interesante. Es de rigor hacer constar que se echa de ver en seguida que, si bien se ha procurado dotar a esta gran sala de todo género de comodidades, como lo prueba el hecho de que todas las localidades sean de butaca, lo mismo las del patio que las de anfiteatros, se ha gastado poco en el capítulo de la decoración. $Y$, sin embargo, la sala presenta un golpe de vista no sólo decorativo, sino bello, aunque es de rigor decir que esa decoración, esa belleza, son distintas de las que habitualmente se emplean en las salas de espectáculos» (38).

Pero todo lo que hizo del Monumental una de las grandes obras de Madrid de los años veinte se ha perdido en las sucesivas intervenciones que ha sufrido el edificio desde 1950.

\section{CONCLUSIONES}

Anasagasti fue un arquitecto especializado en cines y teatros, viajero, pintor, profesor y académico, facilitando la llegada a España de los postulados del Movimiento Moderno, con sus propuestas para concursos y edificios que recuerdan la integración de las artes de las tendencias centroeuropeas.

Por otra parte, el cinematógrafo era el espectáculo de la modernidad y alcanzó una difusión inesperada y masiva; tanto es así que en España se contaba en 1925 con 1.497 cines, que suponía casi la décima parte del total europeo (39), lo que supone realzar aún más si cabe el papel de pioneros que tuvieron Teodoro de Anasagasti o Luis Gutiérrez Soto en estas tipologías.

Esto permitió a Anasagasti preparar un visionario recopilatorio de medidas, referidas a la arquitectura y las instalaciones, del que el Monumental fue su mejor exponente. Y es en los cines donde el arquitecto vasco encontró la oportunidad perfecta para demostrar con hechos aquello que no había logrado defender de manera convincente en sus escritos, esto es, que el hormigón tenía grandes posibilidades formales.

Así pues, Anasagasti logró mediante el trabajo dedicado a los cines acercarse a los postulados de la arquitectura moderna. Así se desprende del hecho de que basara los proyectos en la adecuación al programa, buscando una solución formal sencilla, o que creara un nuevo tipo capaz de adaptarse a cualquier solar, desprendiéndose de las modas academicistas.

Todo un ejemplo de actitud profesional, más allá de los resultados formales, técnicos y tecnológicos empleados, que bien debería replicarse en estos convulsos momentos, casi 100 años después. Lo que avala la necesaria puesta en valor del trabajo de Anasagasti. 


\section{REFERENCIAS}

(1) Fernández Shaw, C. (1949). Un recuerdo a Teodoro Anasagasti. Cortijos y Rascacielos (53).

(2) Moya, L. (1957). Teodoro Anasagasti. Revista Nacional de Arquitectura (191): 13.

(3) Apraiz, E. (1960). Un arquitecto vasco olvidado. Teodoro Anasagasti y Albán. Nueva Forma (90-91).

(4) Fullaondo, J. D. (1971). Anasagasti, poesía olvidada. Arquitectura, enero.

(5) García Morales, M. V. (1979). Teodoro Anasagasti, 1880-1938 (Tesina de licenciatura).

(6) Sainz de los Terreros, L. (1909). La pensión de arquitectura en Roma. La Construcción Moderna (6): 108-110.

(7) Flores, C. (1983). Teodoro de Anasagasti: Enseñanza de la arquitectura. Arquitectura (64): 36.

(8) Bode, Paul, et al. (1957). Kinos: Filmtheater und Filmvorführräume, München: Callwey.

(9) Cladel, G., Feigelson, K., Gevaudan, J.-M. (2001). Le cinéma dans la cité, Paris: Kiron/Félin.

(10) Hänsel, S., Schmitt, A. (1995). Kinoarchitektur in Berlin 1895-1995, Berlin: Reimer.

(11) Lacloche, F. (1981). Architectures de cinemas. Collection Architecture «Les Bâtiments», Paris: Éditions du Moniteur.

(12) Melnick, R., Fuchs, A. (2004). Cinema Treasures, A New Look at Classic Movie Theaters. MIB Publishing Company.

(13) Naylor, D. (1981). American Picture Palaces. The Architecture of Fantasy, New York: Prencite Hall Press.

(14) Schliepmann, H. (1914). Lichtspieltheater: eine Sammlung ausgeführter Kinohauser in gross-Berlin, Berlin: Ernst Wasmuth A.G.

(15) Stindt, O., Zucker, P. (1931). Lichtspielhauser Tonfilmtheater, Berlín: E. Wasmuth.

(16) Vergnes, E. (1925). Cinémas. Vues extérieures et intérieures, details, plans, Paris: Librairie Générale de l’Architecture et des Arts Décoratifs.

(17) Wilms, F. (1928). Lichtspieltheaterhauben, Berlín: E. Wasmuth.

(18) Zucker, P. (1926). Theater und Lichtspielhauser, Berlín: E. Wasmuth.

(19) Cebollada, P., Santa Eulalia, M. G. (2002). Madrid y el cine. Panorama filmográfico de cien años de historia, Madrid: Consejería de Educación de la Comunidad de Madrid.

(20) De la Madrid, J. C. (coord.) (1996). Primeros tiempos del cinematógrafo en España, Oviedo: TREA.

(21) Gutiérrez Cabrero, L. A. (1986). Arquitectura moderna y cine: su estructura comparada como principio objetivo para la comprensión y creación arquitectónica (Tesis doctoral). Madrid.

(22) Anasagasti, T. (1919). El cine moderno. La Construcción Moderna (3): 25. Madrid.

(23) Anasagasti, T. (1911). IX Congreso Internacional de Arquitectos en Roma; resumen de las sesiones. Arquitectura y Construcción (232): 322. Madrid.

(24) VV. AA. (2004). Anasagasti. Obra Completa. Exposición organizada por el Ministerio de Fomento, 2 de diciembre de 2003-26 de enero de 2004. Madrid: Ministerio de Fomento.

(25) Recknagel-Sprenger, W. (1972). Manual de calefacción y climatización (incluido preparación de agua de consumo y técnica del frío), pp. 769-771, Editorial Blume.

(26) Banham, R. (1975). La arquitectura del entorno bien climatizado, Infinito.

(27) VV. AA. (2000). Mutaciones, p. 130, ACTAR.

(28) Nagengast, B. (1999). Early Twentieth Century Air-Conditioning Engineering. ASHRAE Journal, March, p. 61.

(29) Bodinus, W. S. (1999). The Rise and Fall of Carbon Dioxide Systems. ASHRAE Journal, April, p. 39.

(30) Urrutia, A. (1997). Arquitectura española siglo XX, pp. 218-219, Ediciones Cátedra, S. A.

(31) Anasagasti, T. (1923). Características del cine. La Construcción Moderna (21): 334-340, noviembre.

(32) Anasagasti, T. (1923). El edificio. La Construcción Moderna (21): 341-355, noviembre.

(33) Monumental Cinema. Un nuevo salón cinematográfico. $A B C$, 20 de octubre de 1923, p. 6.

(34) Betancor Pérez, F. (2000). Las Palmas de Gran Canaria y sus cines olvidados: aproximación a la historia de la arquitectura cinematográfica a través de los proyectos que quedaron en papel. En Coloquio de Historia Canario-Americana, XIII, p. 3038, Las Palmas: Ediciones Cabildo de Gran Canaria.

(35) Gómez de la Serna, R. (1923). La obra de arte de Anasagasti. La Construcción Moderna (21): 356, noviembre.

(36) Alcántara, F. (1923). Anasagasti, constructor. La Construcción Moderna (21): 356, noviembre.

(37) Francés, J. (1923). La estética del cine. La Construcción Moderna (21): 356, noviembre.

(38) Donosty, J. M. (1924). Anasagasti y su gran cinematógrafo. La Construcción Moderna (1): 10-12, enero.

(39) Gubern, R., et al. (1995). Historia del cine español, p. 88, Madrid: Ediciones Cátedra, S. A. 